\title{
ANALISIS SAINS TERHADAP PENDAPAT BEBERAPA MUFASIR DALAM MENJELASKAN QS. YAASIIN AYAT 80 TENTANG BAHAN BAKAR
}

\author{
Saepulloh
}

STAI Miftahul Huda Al-Azhar

asepsaepullohcgd@gmail.com

\begin{abstract}
The diversity of thought patterns among the interpreter of Holy Qur'an in interpreting verses, especially with regard to the scientific miracles of the Qur'an is something interesting to study. The Qur'an was revealed not to explain science, but as a guide for those who are pious. However, many of the verses of the Qur'an are calling for thinking, so it is inevitable that the motivation of the exegete to study verse by verse will continue to develop in harmony with scientific disciplines, trends, and the development of science and technology in their lifetime.

The problem in this research is the differences of opinion some interpreters of Holy Qur'an are quite significant in interpreting QS. Yaasiin verse 80, by raising six opinions of the interpreter of Holy Qur'an representing classical and contemporary of interpreters of Holy Qur'an.

The purpose of this study is to uncover the background of the Holy Quran's interpreters dissent, looking for points of similarity through scientific analysis. Thus, this research includes qualitative research with a literature study approach. The primary data sources are obtained from the Qur'an commentaries, science books and other sources.

The research step starts from the presentation of data from several Holy Quran's interpreters in the study of the verse under study along with the bibliography to determine the development of science in
\end{abstract}


its time. Then these opinions are clarified to find out the differences and similarities, then reviewed through a scientific analysis approach.

From the results of the study, identified three main opinions of Holy Qur'an's interpreters in interpreting the QS. Yaasiin paragraph 80, namely; First, opinions about the fuel of al-'afar and al-marh (a type of green plants in the country of Hijaz). Second, the opinion that states fuel in the process of photosynthesis, and the third opinion about fuel in the form of coal.

The results of the study showed a relationship (equation) between these commentaries in terms of the energy products produced and their utilization. Different in terms of the shape of the fuel, but the molecular structure (atom $\mathrm{C}$ ), the combustion process (O2 as an oxidizer) and the product of combustion $(\mathrm{CO} 2+\mathrm{H} 2 \mathrm{O}+\mathrm{E})$ are the same. Thus, scientific analysis makes the same concept from the opinions of several different interpreters of Holy qur'an.

Keywords: Interpreters of Holy Quran, fuel, photosynthesis, science.

\begin{abstract}
Abstrak
Keragaman pola fikir di kalangan mufassirin dalam menafsirkan ayat, khususnya yang berkenaan dengan kemukjizatan ilmiah Al-Quran merupakan sesuatu yang menaarik untuk diteliti. Al-Quran diturunkan bukan untuk menjelaskan sains, melainkan sebagai petunjuk bagi orangorang yang bertaqwa. Akan tetapi banyak dari ayat Al-Quran yang menyeru untuk berfikir, sehingga tidak dapat dipungkiri motivasi mufassir untuk mengkaji ayat demi ayat akan terus berkembang selaras dengan disiplin ilmu, kecendrungan, serta perkembangan sains dan teknologi semasa hidup mereka.

Permasalahan dalam penelitian ini adalah adanya perbedaan pendapat beberpa mufassir yang cukup signifikan dalam menafsirkan QS. Yaasiin ayat 80, dengan mengangkat enam pendapat mufassir yang mewakili mufasiir klasik dan kontemporer.

Tujuan dari penelitian ini adalah menguak latar belakang perbedaan pendapat mufassirin, mencari titik persamaan melalui analisis sains. Dengan demikian, penelitian ini termasuk penelitian kualitatif
\end{abstract}


dengan pendekatan studi pustaka. Adapun sumber data primer didapat dari Al-Quran, kitab-kitab tafsir, buku-buku sains dan sumber lainnya.

Langkah penelitian dimulai dari penyajian data beberapa pendapat mufassir dalam kajian ayat yang diteliti berikut bibliograpinya untuk mengetahui perkembangan sains pada masanya. Kemudian pendapat-pendapat tersebut diklarifikasikan guna mengetahui letak perbedaan dan persamaannya, selanjutnya ditinjau melalui pendekatan analisis sains.

Dari hasil kajian, diidentifikasi tiga pendapat pokok mufassir dalam menafsirkan QS. Yaasiin ayat 80, yaitu; Pertama, Pendapat yang tentang bahan bakar al-'afar dan al-marh (sejenis tumbuhan hijau di negri Hijaz). Kedua, pendapat yang menyatakan bahan bakar dalam proses fotosintesis, dan ketiga pendapat tentang bahan bakar dalam bentuk batu bara.

Hasil dari penelitian menunjukan adanya hubungan (persamaan) antara mufassir tersebut yakni dalam hal produk energi yang dihasilkan dan pemanfaatannya. Berbeda dalam hal bentuk bahan bakar, akan tetapi struktur molekul (atom $\mathrm{C}$ ), proses pembakaran $\left(\mathrm{O}_{2}\right.$ sebagai oksidator) dan produk hasil pembakarannya $\left(\mathrm{CO}_{2}+\mathrm{H}_{2} \mathrm{O}+\mathrm{E}\right)$ adalah sama. Dengan demikian, analisis sains menjadikan satu konsep yang sama dari pendapat beberapa mufassir yang berbeda.

Kata Kunci: mufassir, bahan bakar, fotosintesis, sains.

\section{PENDAHULUAN}

Salah satu dari sisi keagungan al-Quran adalah mukjizat ilmiah, terdapat banyak ayat-ayat dalam al-Qur'an yang mengisyaratkan faktafakta ilmiah sejak 14 abad yang silam dan baru diketemukan di era sekarang ini. Banyak ayat Al-Qur'an yang mengajak kita untuk merenung, berfikir dan menggunakan akal kita dalam memahami kebesaran-Nya.

Seiring dengan perkembangan sains dan teknologi, al-Qur'an sering dikaitkan dengan kemukjizatan ilmiahnya. Tentu hal ini seperti "aneh", karena al-Quran bukanlah kitab sains, akan tetapi pengungkapan fakta ilmiah al-Qur'an akhir-akhir ini mau tidak mau membuka peluang bagi siapa saja yang mau mempelajari dan 
menelitinya. Dari sini, muncullah berbagai macam metode dan corak tafsir sebagai salah satu cara memahami isi kandungan al-Qur'an.

Kemampuan setiap orang dalam memahami isyarat ilmiah alQur'an tentu tidaklah sama, termasuk sekelas mufassir pun. Banyak faktor penyebab seperti; tingkat daya nalar, kecendrungan disiplin ilmu, latar belakang, dan perkembangan ilmu pengetahuan semasa hidup masing-masing. Di kalangan mufassir, perbedaan pendapat menjadi sunnatullah dan tidak dilarang selama pendapat mereka tidak bertentangan dengan menggunakan kaidah-kaidah dasar tafsir yang telah ditetapkan.

Salah satu ayat yang dianggap mengandung unsur mukjizat ilmiah al-Quran adalah QS Yaasin ayat 80 yang artinya:

"Dialah (Allah) yang telah menjadikan untukmu api dari kayu yang hijau, maka kamu tiba-tiba menyalakan (api) dari kayu itu” (Terjemah al-Quran, Depag RI, 1992 : 714).

Secara sepintas, ayat di atas sepertinya tidak mengandung unsur mukjizat ilmiah al-Qur'an, karena setiap orang juga tahu maksud ayat tersebut berdasarkan terjemahan umum yang biasa digunakan. Akan tetapi, bagi orang-orang yang berfikir lebih dalam, mereka akan menemukan isyarat-isyarat ilmiah yang membutuhkan pengkajian lebih mendalam berdasrkan kaidah tafsir dan perkembangan ilmu pengetahuan. Salah satu isyarat yang dimaksud adalah lafadz as-syajar al-akhdlar yang secra harfiah mengandung arti "pohon hijau". Mengapa lafadz as-syajar (pohon) harus disipati dengan al-akhdlar (yang berwarna hijau)? Mengapa tidak warna lain? Apa rahasia di balik semua itu? Itulah beberapa dari banyak pertanyaan yang membutuhkan jawaban guna menyingkap rahasia dan isyarat ilmiah al-Quran pada ayat tersebut.

Dari fenomena tersebut, penulis merasa tertarik untuk meneliti khusus ayat tersebut (QS Yaasin ayat 80) berdasarkan pengkajian pendapat beberapa mufassir yang penulis anggap bisa mewakili pendapat klasik dan kontemporer sesuai dengan masanya masingmasing mufassir dan dikomparasikan antara perbedaan dan persamaa pendapat mereka berdasarkan analisis dan tinjauan sains kekinian. 
Saepulloh | Analisis Sains Terhadap...

\section{METODE}

Dalam penelitian ini, metode yang digunakan adalah metode kualitatif. Menurut Bogdan dan Taylor yang dikutif oleh Lexi J. Maleong (2000:3) yang dimaksud dengan metode kualitatif adalah suatu prosedur penelitian yang menghasolkkan data-data deskriptif yang berupa fakta-fakta tertulisatau lisan dari orang-orang atau prilaku yang diamati. Adapun teknik yang digunakan adalah studi pustaka, yakni survei terhadab buku-buku bahan bacaan termasuk kitab-kitab tafsir yang bherhubungan dengan permasalahan teoritik semata, sehingga penggalian data pun berorientasi pada pengkajian kitab-kitab tafsir, buku-buku Ilmu Pengetahuan Alam dan sains, jurnal, majalah dan lain sebagainyatanpa harus mengangkat data empirik lapangan (Wahyudi, 1991).

Adapun langkah-langkah yang ditempuh dalam penelitian ini adalah sebagai berikut:

1. Menetukan jenis data

Jenis data yang digunakan adalah data kualitatif. Menurut Suharsimi Arikunto ( 1998: 245) menyatakan bahwa data kualitatif merupakan data deskriptif yang digambarkan dengan kata-kataatau kalimat yang dipisah-pisahkan berdasarkan kategori untuk memperoleh kesimpulan

2. Sumber Data

Sumber data dalam penelitian ini adalah literatur atau dokumendokumen tertulis yang terdiri dari sumber data primer dan sekunder. Data primer penelitian ini adalah Tafsir Al-Quran; Tafsir al-Azhar, Tafsir fii dzilal al-Quran, Tafsir Ibnu Katsir, tafsir al-Jalalain dan kitab-kitab tafsir pendukung lainnya. Termasuk ke dalam data primer adalah buku-buku biologi, fisika, kimia dan buku sains yang berhubungan dengan permasalahan penelitian. Data sekunder peneliti dapat dari jurnal ilmiah, majalah, CD dan sumber data lainnya.

3. Teknik pengumpulan data

Menurut Suharsimi Arikunto (1999:5), langkah-langkah yang digunakan dalam tnjauan pustaka ada empat macam, yakni : 
a. Melakukan inventarisasi judul-judul bahan [ustka yang berhubungan dengan masalah penelitian.

b. Melakukan pemilihan isi dalam bahan pustaka.

c. Melakukan penela'ahan jterhadap isi tulisan dalam pustaka penela'ahan. Hal ini dilakukan dengan cara pemilihan unsur-unsur metodologi yang berhubungan dengan masalah penelitian.

d. Melakukan pengelompokan hasil bacaan yang telah ditulis sesuai dengan rumusan yang telah tercantum dalam masalah penelitiaan.

4. Analisis data

Menurut Paton yang dikutif oleh Lexi J. Maleong (1999:103), analisis data adalah proses mengatur urutan data, mengorganisasikannya ke dalam suatu pola kategori dalam satuan urutan data. Maka dalam penelitian ini, analisis data bermaksud untuk mengorganisasi data dan menjadikannya dalam pola yang teratur.

Analisis data yang digunakan dalam penelitian ini adalah dengan menggunkan langkah-langkah sebgai berikut:

a. Mengelompokan data-data tertulis tentang interpretasi / penafsiran beberapa mufassir mengenai QS. Yaasin ayat 80 sesuai dengan corak metode penafsiran mereka masing-masing.

b. Mengelompokan data-data tertulis tentang tinjauan sains terhadap pendapat para mufassir tersebut.

c. Mengkategorikan data-data tertulis yang berhubungan dengan masalah yang diteliti dalam pola pikiran tertentu dan sekaligus menghubungkan dan membandingkannya.

d. Menganalisis data tertulis Ddari hasil perbandingan dengan metode deskriptif dalam kerangks deduktif.

5. Generalisasi

Kesimpulan atau generalisasi dalam suatu penelitian merupakan hasil dari suatu proses, yaitu memisahkan sesuatu dari suatu tempat ke tempat lain (Suharsimi, 1996 : 346). Pengambilan 
Saepulloh | Analisis Sains Terhadap...

kesimpulan dalam penelitian ini adalah berdasarkan data yang terkumpul dan tidak keluar dari batasan-batasan data tersebut.

\section{KAJAN PENDAPAT MUFASSIR}

\section{Terjemah QS. Yaasiin Ayat 80}

"Dialah (Allah) yang telah menjadikan untukmu api dari kayu yang hijau, maka kamu tiba-tiba menyalakan (api) dari kayu itu” (Terjemah al-Quran, Depag RI, 1992 : 714).

\section{Pendapat At-Thabari}

Nama lengkap at-Thabari adalah Muhammad bin Jarir bin Yazid bin Khalid bin Katsir Abu Ja'far at-tabariat Tabari, lahir pada tahun $224 \mathrm{H}$ dan wapat pada tahun $310 \mathrm{H}$ di Baghdad Irak. Kitab Jami'ul Bayan Fii Tafsiir al-Quran karangan at-Tabari merupakan salah satu rujukan penting, terutama bagi mereka yang menaruh perhatian besar terhadap tafsir dengan corak bi al-ma'tsuur. Dalam menafsirkan ayat belaiu mendasarkan kepada hadits, pendapat sahabat dan tabi'in dengan periwayatan sanad yang lengkap, kemudian men-tarjihkannya. Terkadang beliau juga menerangkan gramatikal bahasa bila diaanggap perlu dan juga istinbat (keterkaitan) hukum (Manna alQattan, 2001: 502).

Dalam menafsikan QS. Yaasin ayat 80, at-Tabari mengkorelasikan dengan ayat sebelum dan sesudahnya. Pertamatama beliau menukil pendapat yang dianggap sependapat dengannya dalam mena'wilkan ayat tersebut. Menurut beliau, kata ja'ala (menjadikan) mengandung arti akhraja (mengeluarkan), yaitu :" Dialah (Allah) yang mampu mengeluarkan api dari kayu hijau....". Kata as-Syajar merupakan bentuk plural dari kata syajaratun yang mempunyai arti pohon (Jami'ul bayan fii tafsiir al-Qur'an, hal: 2122).

\section{Pendapat Ibn Katsir}

Nama lengkap Ibnu Katsir adalah Isma'il bin Amral Qurasyi bin Katsir al-Bashri ad-Dimasyqi I'maduddin Abul Fida al-Hafidz alMuhadits as-Syafi'i, lahir pada tahun $705 \mathrm{H}$ dan wapat pada tahun 
$774 \mathrm{H}$, setelah menempuh kehidupan panjang yang syarat dengan keilmuan ( Manna al_qattan, 2001:257).

Diantara ciri khas tafsir Ibnu Katsir adalah "tafsir al-Quran dengan al-Quran". Tafsirnya banyak memuat pemaparan ayat-ayat yang bersesuaian maknanya (munasabah), kemudian diikuti dengan hadits-hadits marfu' yang ada relevansinya dengan ayat (yang sedang ditafsirkan) serta menjelaskan apa yang dijadikan hujjah dari ayat tersebut, kemudian diikuti pula dengan atsar para sahabat, pendapat tabi'in dan ulama salaf sesudahnya. Termasuk keistimewaanya pula adalah selalu disertakannya peringatan-peringatan akan cerita israailiyyat ( cerita-cerita yang masih dipertanyakan kebenarannya) tertolak yang banyak tersebar dalam tafsir-tafsir bi al-ma'tsuur.

Dalam menafsikan QS Yaasiin ayat 80, Ibnu Katsir mengkorelasikan dengan tiga ayat sebelumnya. Menurut Beliau, “ alladzii ja'ala lakum ....yakni dialah (Allah) yang memulai penciptaan pohon (as-Syajar) dari air, sampai jadilah sebuah pohon yang hijau daunnya dan dapat berbuah. Kemudian pohon ini akan menjadi kering dan jadilah kayu bakar untuk menghasilkan api. Ini diisyaratkan dengan "... naaran faidzaa antum minhu tuuqiduuna". Demikianlah kekuasaan Alloh yang mampu menciptakan segala sesuatu atas kehendaknya.

Penjelasan beliaudiperkuat dengan mengutip pendapat Qatadah bahwa yang dimaksud dengan as-syajar al-akhdar adalah al-marh dan al-afar, yaitu dua jenis pohon yang tumbuh di egri Hijaz. Konon kedua pohon ini diambil batang mudanya, kemudian digosokgosokan satu dengan bagian lainnya akan menimbulkan percikan api. Ibnu abas berpendapat bahwapada setiap pohon mengandun ( dapat menyalakan) api, termasuk al-marh dan al-afar (Tafsiir alQuran al'Adziim, juz 3, hal: 559).

\section{Pendapat Jalaludin as-Suyuti}

Nama lengkap Jalaluddin as-Suyuti adalah Abu al-Fard Abdurrahman bin Abu Bakar bin Muhammad Jalaluddin as-Suyuti. Ia lahir di Kairo Mesir pada tanggal 3 Oktober $1445 \mathrm{M}$ dan wafat pada tangggal 17 Oktober 1505 M (Ensiklopedi, 1997:324). 
As-Suyuti menggunakan metode at-tahlili, yaitu suatu metode tafsir yang mufassirnya berusaha menjelaskan kandungan ayat-ayat al-Quran sebagai manatercantum dalam al-Quran. Segala segi yang dianggap perlu oleh mufassir diuraikan dari mulai kosa kata, asbab an-nuzul, munasabah dan lainnya yang berkaitan dengan jteks atau kandungan ayat.

Dalam menjelaskan QS. Yaasiin ayat 80, beliau sependapat dengan Ibnu Katsir, akan tetapi beliau menambahkan dengan menjelaskan bahwa ayat tersebut merupakan dalil akan kekuasaan Allah menghidupkan yang mati dengan memberikan suatu realita kekuasan-Nya menciptakan api dari pohon hijau yang banyak mengandung air dan kayu. Padahal, sifat air dapat memadamkan api, dan api muncul dari pembakaran kayu yang berair. Bukankah yang demuikian merupakan kekuasaan Allah? Demikian as-Suyuti ( Tafsir al-Jalalain, bagian 2, hal ; 365).

\section{Pendapat Sayid Qutub}

Nama lengkapnya aadalah sayid Qutub Husain syadzili. Lahir di mausyah, salah satu wilayah provinsi as-Syut, dataran tinggi Mesir pada tanggal 09 Oktober $1906 \mathrm{M}$ pada masa repolusi rakyat Mesir (Shalah Abdul Fathah alkhalidi, 2003 : 36).

Metode tafsir yangdigunakan Sayid Qutub adalah memaparkan setiap kumpulan ayat-ayat al-Qur'an yang diikat oleh sebab khusus dan dinaungi oleh naungan khusus, yang kemudian beliau paparkan dalam bentuk "'ibrah al-Quran".

Dalam menafsirkan QS. Yaasin ayat 80, Sayid Qutub mengkorelasikannya dengan tiga ayat sebelumnya dan satu ayat sesudahnya. Beliau menganggap adanya munasabah (kesesuaian) pada kelompok ayat yang berdampingan tersebut (QS Yaasin ayat 77-81), yakni sama-sama menjelaskan kekuasaan Allah dalam menjadikan sesuatu di luar jangkauan fikiran manusia.

Menurut beliau, ayat ini merupakan ayat yang mengandung mukjizat ilmiah. Energi panas yang terkandung dalam pohon hijau ( as-syajar al -akhdlor) tersebut berasal dari energi matahari (Thaaqat as-syamsi) yang diserapnya. Energi matahari yang diserap pohon 
hijau tersebut akan terlibat dalam suatu proses yang menghasilkan air (salah satu unsur penyusun air adalah oksigen). Hasil akhir dari proses tersebut merupakan komponen yang nantinya akan menyusun tubuh pohon hijau tersebut (kayu), dan dari kayu inilah akan didapatkan api sebagai bahan bakar. Tapi sayang, Sayid Qutub tidak menjelaskan proses penyerapakan energi matahari tersebut. Di akhir penjelasannya, lia mengatakan bahwa ia tidwak mengetahui tentang rahasia-rahasia di balik semua kejadian itu (prosesnya). Andai saja kita mengetahuinya, niscaya kita akan hidup dalam ibadah dan selalu bertasbih memuji keagungan ilahi (Tafsir Fii Dzilal al-Qur'an, hal : 2977).

\section{Pendapat HAMKA}

Nama aslinya adalah Abdul Malik Karim Amrullah. Lahir di Minangkabau, Sumatra Barat, pada tanggal 16 Februari $1908 \mathrm{M}$ dan meninggal padaa tanggal 24 Juli 1981 M ( Yunan Yusuf, 2004: 52).

Dalam menjelaskan QS. Yaasin ayat 80, HAMKA menjelaskan bahwa selain dari kekuasaan Allah menghidupkan tulang belulang yang lapuk setelah terpendam sekian ribu tahun lamanya, kekuasaan Allah juga menimbulkan api untuk manusia dari pohon kayu yang hijau seperti pohon tusam dan pinus yang mengandung minyak yang dapat dinyalakan. Selain dari itu, beliau juga berpendapat bahwa boleh jadi yang dimaksud ayat tersebut adalah batu bara berdasarkan keterangan ahli-ahli.

Batu bara yang tersimpan dalam bumi yang sekrang banyak digali orang untuk menghidupkan mesin-mesin dan bahan bakar adalah anjutan atau proses alamiah yang telah berlaku jutaan tahun yang berasal dari pohon-pohon kayu besar di zaman purbakala. Pohon-pohon besar tersebut terbenam ke balik bumi dan tertimbun lau dimasak oleh panas matahri dan bumi sehingga berangsur menjadi batu bara. Kelanjutan ayat "... maka tiba-tiba kamu menyalkan api daripadanya...” yaitu menyalkan api dari pohon besar hijau yang telah berubah menjadi batu bara melaui proses tersebut (tafsir al-Azhar, juz 23, hal: 102-103). 
Saepulloh | Analisis Sains Terhadap...

\section{Pendapat Muhammad Quraish Shihab}

Muhammad Quraish Shihab lahir di Sindereng Rappang, Sulawesi Selatan pada tanggal 16 Februari 1944. Beliau adalah salah satu cendikian muslim dalam bidang ilmu-ilmu al-Qur'an dan berhasil membuat karya terkenal yaitu tafsir al-Mishbah dan buku mukjizat ilmiah al-Qur'an.

Dalam menafsirkan QS. Yaasin ayat 80, Quraish Shihab menjelaskan dengan mengutif pendapat ahli sains modern bahwa kata as-Syajar al-akhdlar sebagai "zat hijau daun" atau yang dikenal dengan nama chlorophyill (klorofil). Allah SWT menjadikan dari pohon hijau suatu energi.

Dalam plasma sel-sel tumbuhan terdapat Zat yang dinami chromatophone (pembawa zat warna). Bentuk dan warnanya adalah kuning, merah, jingga dan hijau. Dari semua zat warna tersebut yang paling banyak dan penting adalah zat hijau daun (chloropyll) yg terdapat pada daun dan sebagian batang dan ranting-ranting muda.

Klorofil terdiri dari ikatan-ikatan zat karbon, hidrogen, nitrogen dan magnesium.aktifitas utama dari zat klorofil ini adalah menjelmakan zat organik dari zat anorganik sederhana dengan bantuan sinar matahari. Proses ini disebut dengan photosynthesis (fotosintesis), yakni mengadakan sintesis dengan photon (cahaya). Jelasnya, klorofil mengubah tenaga radiasi matahari menjadi tenaga kimiawimelalui proses fotosintesis atau dengan kata lain menyimpan tenaga matahari dalam tumbuh-tumbuhan berupa makanan dan bahan bakar yang nantinya akan muncul sebagai api atau tenaga kalori sewaktu terjadi pembakaran. Proses pembakaran ini disebut dengan respirasi yang dalam bahasa al-Qur;annya "... faidzaa antum minhu tuuqiduuna.." yang artinya.. maka secara serta merta tanpa campur tangan kamu, kamu dapat menyalakan api..). demikian menurut Quraish Shihab ( Mukjizat al-Qur'an, 2003:188).

\section{ANALISIS SAINS}

\section{Fotosintesis}

Tinjauan sains ini dimulai dari proses fotosintetis, yakni dari pendapat Sayid Qutub dan M. Quraish Shihab. Pendapat ini 
didahulukan karena beberpa alasan, diantaranya fotosintesis merupakan langkah awal yang menghasilkan produk guna menyusun tubuh tumbuhan yang nantinya akan menjadi bahan bakar. Fotosintesis merupakan suatu proses rumit yang memproduksi makanan bagi hampir seluruh kehidupan di dunia, baik secara langsung maupun tidak langsung.

Tumbuhan erupakan organisme autotrof, artinya dapat membuat makanan sendiri melalui proses fotosintesis. Fotosintesis adalah reaksi biokimia pembentukan zat makanan seperti karbohidrat yang dilakukan tumbuhan, terutama tumbuhan yang mengandung zat hijau daun atau klorofil dengan bantuan sinar matahari. Secara garis besarnya, proses fotosintesis dapat digambarkan seperti narasi berikut:

Tumbuhan bisa mendapatkan karbondioksida $\left(\mathrm{CO}_{2}\right)$ dari udara yang masuk ke daun tumbuhan melalui stomata atau mulut daun. Sementara air $\left(\mathrm{H}_{2} \mathrm{O}\right)$ diserap tumbuhan melalui akar yang kemudian disalurkan ke daun melalui batang tumbuhan, yakni jaringan floem. Saat sinar matahari jatuh ke permukaan daun, klorofil menangkap energi dari cahaya matahari tersebut. Cahaya akan melewati lapisan epidermis transfaran, kemudian diteruskan menuju mesofil, dan di mesofil inilah sebagian besar fotosintesis terjadi.

Energi cahaya matahari tersebut kemudian digunakan tumbuhan untuk mengubah air yang diserap dari tanah melaui akar menjadi gula sederhana atau glukosa $\left(\mathrm{C}_{6} \mathrm{H}_{12} \mathrm{O}_{6}\right)$ dan oksigen $\left(\mathrm{O}_{2}\right)$. Selanjutnya, glukosa sebagai cadangan makanan akan didistribusikan ke seluruh jaringan tubuh tumbuhan melalui pembulu kayu (xylem) guna mengganti jaringan atau sel yang rusak dan juga sebagai cadangan makanan dalam bentuk buah dan umbi-umbian. Sementara oksigen yang dihasilkan dari proses fotosintesis akan dilepas tumbuhan ke udara melalui stomata. Oksigen ini kemudian dapat dihirup oleh manusia maupun hewan sebagai oksidator dalam proses resfirasi.

Untuk dapat melakukan proses fotosintesis, tumbuhan membutuhkan empat faktor penting diantaranya; klorofil, cahaya matahari, air, dan karbondioksida. 
Secara umum, reaksi fotosintesis dapat dijelaskan melalui persamaan seperti berikut:

$$
6 \mathrm{H}_{2} \mathrm{O}+6 \mathrm{CO}_{2}+\text { cahaya } \longrightarrow \mathrm{C}_{6} \mathrm{H}_{12} \mathrm{O}_{6}+6 \mathrm{O}_{2}
$$

Keterangan :

- $\mathrm{H}_{2} \mathrm{O}=$ air

- $\mathrm{CO}_{2} \quad=$ karbondioksida

- $\mathrm{C}_{6} \mathrm{H}_{12} \mathrm{O}_{6}=$ glukosa

- $\mathrm{O}_{2} \quad=$ oksigen

Persamaan di atas seolah-olah merupakan rangkuman sederhana dari suatu proses yang sangat rumit. Fotosintesis bukanlah proses tunggal, tetapi dua proses yang masing-masing terdiri dari bnyak langkah. Kedua tahap fotosintesis itu dikenal sebagai reaksi terang, yakni bagian fhoto dari fotosintesis dan siklus Calvin sebagai bagian sintesis (Cmpbell, 2000: 185).

Reaksi terang mengubah energi matahari menjadi energi kimiawi dalam bentuk ATP dan NADPH yang dimulai dari penguraian air (fotolisis), fotoeksitasi klorofil, fhotosistem I dan fotosistem II.

Siklus calvin menggunakan energi dalam bentuk ATP dan $\mathrm{NADPH}$ untuk mengubah $\mathrm{CO}_{2}$ menjadi gula melalui langkah fiksasi $\mathrm{CO}_{2}$, reduksi, dan regenerasi akseptor $\mathrm{CO}_{2}(\mathrm{RuBP})$.

Reaksi terang dan siklus calvin bekerjasama mengubah energi cahaya menjadi energi kimiawi berupa makanan dalam bentuk gula sederhana. Selanjutnya, sekitar 50\% materi organik yang dihasilkan oleh fhotosinteis itu dikonsumsi sebagai bahan bakar untuk respirasi seluler dalam mitokondria sel tumbuhan. Pada sebgian besar tumbuhan, karbohidrat diangkut ke luar daun dalam bentuk sukrosa, suatu disakarida. Setelah sampai di sel nonfotosintetik (tidak berklorofil), sukrosa tersebut menyediakan bahan mentah untuk resfirasi seluler dan banyak sekali jalur anabolik yang mensintesis protein, lipid, dan produk lain. Sejumlah besar gula dalam bentuk glukosa dihubungkan bersama-sama untuk membuat polisakarida selulosa, khusunya pada sel tumbuhan yang sedang tumbuh menuju dewasa. 
Berdasarkan uraian di atas, maka produk fotosintesis akan mengalami banyak jalur yang akan dilauinya. Namun yang terpenting, mengacu pada penelitian ini, produk fotosintesis merupakan bahan bakar penghasil energi yang bermanfaat bagi kehidupan di dunia ini, baik bahan bakar respirasi seluler untuk menghasilkan energi dalam bentuk ATP, maupun bahan bakar yang umum digunakan sehari-hari seperti kayu bakar, minyak bumi, batu bara, dan lain sebagainya.

\section{Respirasi sel}

Energi kimia yang terbentuk dalam molekul organik sebagai hasil dari proses fotosintesis akan dilepas untuk kesinambungan hidup. Proses pelepasan energi yang menyediakan energi untuk keperluan tersebut disebut proses respirasi. Resiprasi merupakan suatu proses reaksi katabolisme yang memecah molekul-molekul gula menjadi molekul anorganik berupa karbondioksida $\left(\mathrm{CO}_{2}\right)$ dan air $\left(\mathrm{H}_{2} \mathrm{O}\right)$ dengan menggunakan energi kimia dalam bentuk ATP sebegai penggerak.Respirasi terdiri dari banyak reaksi yang masing-masing dikatalisasi oleh enzim yang berbeda. Respirasi merupakan kebalikan dari proses fotosintesis dengan rumus persamaan reaksi sebagai berikut :

$$
\mathrm{C}_{6} \mathrm{H}_{12} \mathrm{O}_{6}+6 \mathrm{O}_{2}
$$

$-6 \mathrm{CO}_{2} \rightarrow \mathrm{H}_{2} \mathrm{O}+$ Energi

Tahapan proses respirasi sel terdiri dari : Glikolisi, Dekarboksilasi oksidatif, siklus krebs, transfer elektron,lintasan pentosa fosfat. Setiap tahapan merupakan suatu proses yang rumit, sama seperti hal rumitnya proses fhotosintesis.

\section{Pelapukan Tumbuhan Purba menghasilkan Bahan bakar}

Fosil merupakan sisa-sisa makhluk hidup (hewan dan tumbuhan) yang telah mati dan terbenam di dasar bumi serta telah mengalami pelapukan. Proses pelapukan ini telah mengubah struktur sisa-sisa makhluk hidup tersebut, baik melalui proses biokimia (kimia), maupun biomekanik (fisika) menjadi bentuk baru dengan komposisi kimia yang relatif berbeda dari struktur semula.

Sedimentasi organik dari sisa-sisa tumbuhan purba (berfotosintesis) lambat laun akan berubah menjadi batuan-batuan 
dengan komposisi yang berbeda. Batuan sedimen yang mengandung zat karbon (C) kebanyakan terbentuk dari tumbuhan-tumbuhan yang melapuk (dari zaman carboniferus). Contoh dari batuan ini adalah batu bara yang mempunyai nilai ekonomi tinggi sebagai bahan bakar yang bermanfa'at.

Proses pemmbentukan batu bara secara terperinci menjalani beberapa stadium / fase sebagai berikut ; Pertama, Pembentukan gambut dari sisa tumbuhan yang telah mati. Kedua, terjadinya batu bara muda atau sering disebut lignit ( pada fase ini struktur tumbuhan masih terlihat). Ketiga, terjadinya batu bara, dimana struktur tumbuhan sudah tidak terlihat lagi. Bila temperatur dan tekanan terus meningkat, maka akan terbentuk antrasit dan pada stadium akhirnya akan terbentuk grafit.

\section{Reaksi Pembakaran}

Reaksi-reaksi pembakaran memegang peranan penting dalam kehidupan sehari-hari sebagai sumber energi. Pembakaran bahan bakar kayu, batu bara dan gas bumi yang banyak mengandung unsur karbon (C) akan menghasilkan energi dengan rumus reaksi kimia pembakarannya sebagai berikut :

$\mathrm{CH}_{2} \mathrm{O}+\mathrm{O}_{2}+$ mineral $\longrightarrow \mathrm{CO}_{2}+\mathrm{H}_{2} \mathrm{O}+$ energi (cahaya / panas ) + abu

Percikan api (spark) dibutuhkan untuk memulai reaksi ini. Nyala api yang kita lihat sewaktu pembakaran tiada lain gas-gas dan karbon yang tidak terbakar yang menguap ke udara (Vernon, 1971:07).

\section{PEMBAHASAN}

Perbedaaan pendapat mufassir dalam menjelaskan QS. Yaasin ayat 80 secara spesifik terletak pada penafsiran kata asy-syajar alakhdar (pohon hijau), kata an-naar (api), dan kata tuuqiduuna (kalian menyalakan) dengan penjelasan sebagai berikut :

1. Ibnu katsir dan Jalaludin as-Suyuti menafsirkan kata asysyajar al-akhdar sebagai al-a'far dan al-marh, dua jenis pohon hijau yang tumbuh di negri Hijaz. 
2. Sayid Qutub dan M. Quraish Shihab menafsirkan kata asysyajar al-akhdar sebagai semua tumbuhan hijau yang berfotosintesis, dan kata an-naar ditafsirkan sebagai energi kimiawi.

3. HAMKA menafsirkan kata asy-syajar al-akhdar bahan bakar dalam bentuk batu baru, dan kata an-naar ditafsirkan sebagai api.

Tinjauan sains dimulai dari proses fotosintesis yang akan menghasilkan produk glukosa dan oksigen, glukosa selanjutnya masuk ke jalur metabolisme sel. Persamaan proses fotosintesis sebagai berikut :

$$
6 \mathrm{H}_{2} \mathrm{O}+6 \mathrm{CO}_{2}+\text { cahaya } \longrightarrow \mathrm{C}_{6} \mathrm{H}_{12} \mathrm{O}_{6}+6 \mathrm{O}_{2}
$$

Katabolisme memecah glukosa untuk menghasilkan energi dalam bentuk ATP melalui proses respirasi sel. Anabolisme menyususn glukosa menjadi senyawa yang lebih kompleks untuk menyusun tubuh tumbuhan seperti kayu. Kayu merupakan bahan bakar terutama bila dikeringkan. Apabila kayu tertimbun dalam waktu jutaan tahun, maka akan melapuk dan membentuk batu bara. Proses pembakaran kayu dan batu bara akan menghasilkan energi dalam bentuk energi panas dan cahaya (api), dengan oksigen sebagai aksidator / zat pembakarannya. Hasil pembakaran seluruh bahan bakar menghasilkan produk utama yang sama sebagai berikut:

Bahan bakar (glukosa, kayu, dan batu bara) proses pembakaran

$$
\mathrm{CO}_{2}+\mathrm{H}_{2} \mathrm{O}+\text { Energi }
$$

Dengan demikian, maka energi merupakan konsep yang menjadi titik persamaan dari perbedaan pendapat mufasir melalui analisis sains.

Untuk lebih memudahkan dalam memahaminya, penulis sajikan dalam bentuk bagan yang menggambarkan korelasi pendapat mufassir dalam tinjauan sains seperti di bawah ini : 


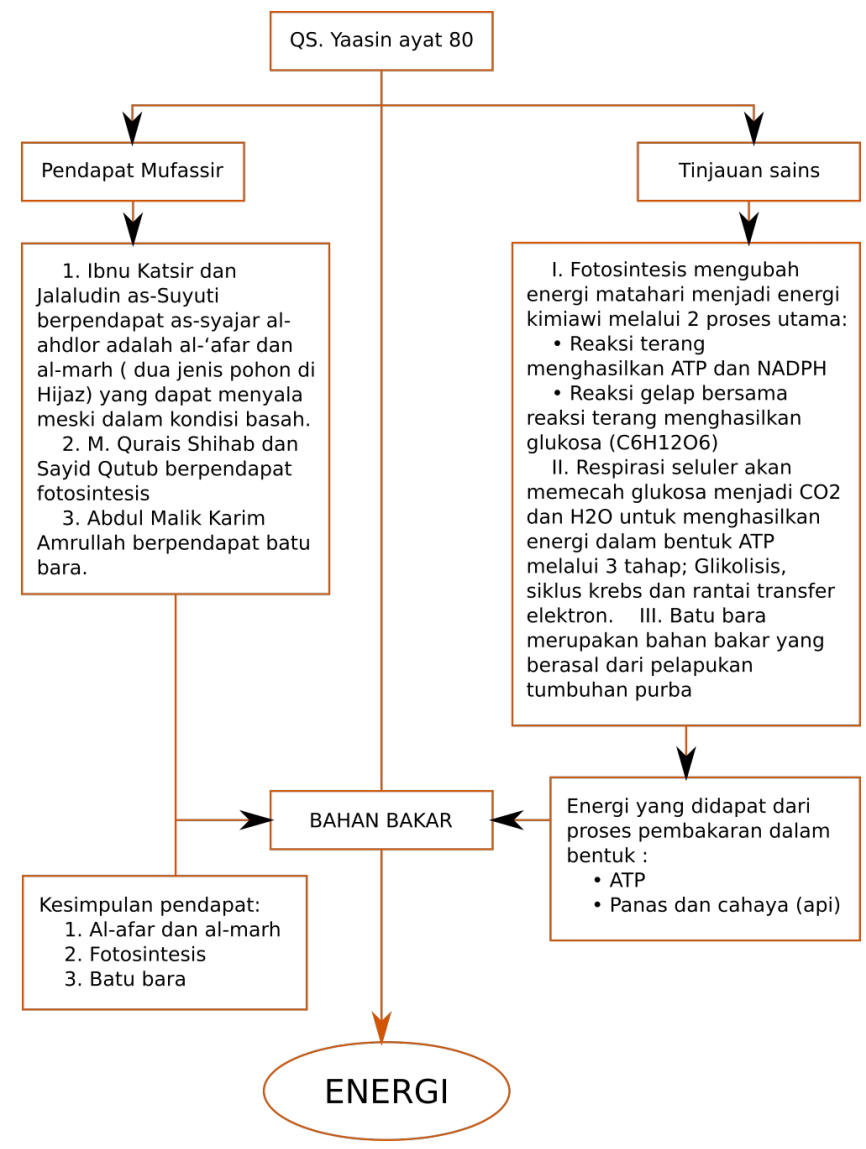

\section{KESIMPULAN}

Berdasarkan kajian pendapat beberapa mufassir dalam menjelaskan QS. Yaasiin ayat 80, tinjauan dan analisis sains tersebut di atas, maka didapat beberapa kesimpulan sebagai berikut:

1. Pendapat yang mengatakan bahwa tafsir QS Yaasin ayat 80 adalah tentang bahan bakar dalam bentuk kayu dari pohon yang bernama al-marh dan al-afar, dua jenis tumbuhan yang tumbuh di negri hijaz. Ini adalah pendapat yang dikemukakan oleh Ibnu Katsir dan Jalaluddin as-Suyuti.

2. Pendapat yang mengatakan bahwa tafsir QS Yaasin ayat 80 adalah tentang bahan bakar dalam bentuk molekul gula sederhana yang dihasilkan tumbuhan hijau melalui proses 
rumit fotosintesis. Pendapat ini dikemukakan oleh M. Quraish Shihab.

3. Pendapat yang mengatakan bahwa tafsir QS Yaasin ayat 80 adalah tentang bahan bakar dalam bentuk batu bara, yakni bahan bakar hasil galian yang berasal dari pelapukan tumbuhan purba. Pendapat ini dikemukakan oleh HAMKA meski beliau juga meninggung bahan bakar dalam bentuk pohon tusam dan pinus.

Perbedaan pendapat mufassir tersebut secara spesefik terletak pada penafsiran lafadz as-syajar al-akhdlar (pohon hijau) dan lafadz tuuqiduuna (menyalakan).

Tinjauan dan analisis sains menunjukan bahwa fotosintesis mempunyai peran penting dalam proses pembentukan bahan bakar, baik bahan bakar dalam metabolisme sel maupun bahan bakar umum yang kita kenal seperti kayu, minyak bumi, batu bara dan lain sebagainya. Fotosintesis menghasilkan gula sederhana dalam bentuk glukosa. Glukosa merupakan bahan bakar untuk menghasilkan energi dalam bentuk ATP melalui proses respirasi seluler. Glukosa yang diproduksi terus akan disalurkan ke seluruh bagian tubuh tumbuhan untuk tumbuh dan berkembang dan kelebihannya akan disimpan sebagai cadangan makanan dalam bentuk buah maupun umbi-umbian. Tumbuhan tingkat tinggi akan tumbuh dan berkembang sampai terbentuknya pohon besar (kayu). Kayu merupakan bahan bakar yang biasa digunakan dalam kehidupan sehari-hari. Jutaan tahun yang lalu, banyak kayu besar yang tertimbun dan melalui proses pemanasan bumi, terbentuklah batu bara, gas, dan minyak bumi yang juga sebagai bahan bakar. Dengan demikian, dalam penelitian kualitatif ini didapat korelasi tentang bahan bakar yang dimaksud mufassir dalam menafsirkan QS yaasiin ayat 80 dalam berdasarkan tinjauan dan analisis sains dalam hal sebagai beikut:

- Struktur molekul bahan bakar, baik al-afar, al-marh, pinus, tusam dan jenis kayu lainnya, maupun glukosa dan bahan bakar hasil bumi (batu bara dan migas) semuanya mengandung unsur karbon (C) sebagai senyawa organik yang relatif banyak. 
- Zat pembakar atau oksidator utama dalam proses pembakaran adalah oksigen $(\mathrm{O} 2)$ sebagai unsur yang memiliki elektronegativitas kuat.

- Proses pembakaran semua bahan bakar menghasilkan produk utama dalam bentuk air (H2O), karbondioksida (CO2) dan energi.

- Bentuk energi yang dihasilkan dapat berupa ATP, panas, atau panas dan cahaya.

\section{DAFTAR PUSTAKA}

At-Thabari tt. Jamii' al-Bayan fii at-Tafsiir al-Qur'an. Daarul Ma'rifah, Beirut, Libanon.

Campbell, Reec-Metchell,.Dkk 2000. Biology, Jilid I. Terjemahan Rahayu Lestari, at all., Biologi. Erlangga, Jakarta.

Departemen Agama RI 2001. Al-Qur'an dan Terjemahan, Diponegoro, Bandung.

Doris L Holmes 1996. Element of Physical Geology, The Ronald Press Company, New York, USA.

HAMKA, Prof., Dr. 1960. Tafsir al-Azhar, Yayasan Latimokong, Surabaya.

Ibnu Kathir tt. Tafsir al-Qur'an al- 'Adziim, Daar al-Jiil, Beirut.

Libanon.

As-Suyuti, Jalaluddin 2001. tafsir al-Jalalain dan Asbab an-nuzul, Sinar Baru al-Gensindo, Yogyakarta.

Lexi J. Maleong 2002. Metode Penelitian Kualitatif, PT Remaja Rosda Karya, Bandung.

Quraish Shihab, M 1998. Mukjizat al-Qur'an, Mizan, Bandung. Manna Al-Qattan 1973. Mabaahits fii 'ulum al-Qur'an, cet ke-3, terjemahan Mudzakir AS, Studi Ilmu-ilmu al-Qur'an, PT Pustaka Litera Antar Nusa, Bogor, 2001.

Sayid Qutub tt. Fii Dzilal al-Qur'an, juz 19-25, Jilid 5, Daar as-Syaruq Beirut, Libanon.

Suharsimi Arikunto 1998. Prosedur Penelitian; Suatu Pendekatan Praktis. Rineka Cipta, Jakarta. 
Yunan Yusuf 2004. Corak Pemikiran tafsir al-Azhar, PT Penamadani, Jakarta. 